\title{
Plenty of Room Left for the Dogmatist
}

\section{Cartesian vs. Dogmatist Accounts of Perceptual Justification}

Barnett (2019) provides an interesting new challenge against Dogmatist ${ }^{1}$ accounts of perceptual justification. For present purposes, the Dogmatist's key claim is the denial of the following 'Cartesian'"2 thesis:

- (PERCEPTUAL INCREDULISM) One is never justified in believing what one perceives unless one has independent evidence that one's perceptual experiences are reliable.

To deny Incredulism is to allow that (some) experiences can provide (some degree of) justification even if you have no independent evidence that they are reliable.

The Cartesian and the Dogmatist also disagree over the relative importance of one's own experiences compared with other peoples' experiences. The Cartesian accepts the following:

- (PERCEPTUAL IMPARTIALITY) Having a perceptual experience can never give you substantially stronger justification for a perceptual belief than you would get from knowing that another person has had such an experience.

Given a Cartesian view of your own experience, "it would seem irrationally chauvinistic to count one's own experiences as stronger evidence of the truth than another person's experiences, unless you have some evidence suggesting that your experiences really do amount to more reliable evidence." (Barnett, 2019, 28)

Whereas the Dogmatist accepts:

- (PERCEPTUAL PARTIALITY) Having a perceptual experience can sometimes give you substantially stronger justification for a perceptual belief than you would get from knowing that another person has had such an experience.

\footnotetext{
1 The label 'Dogmatism' is due to Jim Pryor's (2000) seminal paper 'The Skeptic \& The Dogmatist'.

2 Barnett generally uses the labels 'Cartesian' vs. 'Anti-Cartesian' - Dogmatism is then counted as one form of Anti-Cartesianism, whilst Epistemological Disjunctivism (e.g. McDowell 1994, Pritchard 2012) is another kind of Anti-Cartesianism.
} 
To be clear: the idea is not just that we have a special, introspective way of knowing about our own experiences (the Cartesian will happily accept this too.) The idea is that the mere fact of my having the experience can provide some degree of justification for a perceptual belief, quite apart from my knowing anything about this experience - and in particular, quite apart from knowing whether my own perceptual experiences are generally reliable.

\section{A Diachronic Problem for Dogmatism}

Given the Dogmatist commitment to Perceptual Partiality, let's now consider the case where the 'other person' that you know to have had the experience is your own future self.

'(ANTICIPATED EXPERIENCE) Shortly before noon, you are wearing a blindfold and facing a wall. You know that at noon, the blindfold will be removed, and that when it is, you will have an experience as of a red wall.' (Barnett, 2019, 21)

It seems that the Dogmatist cannot allow mere knowledge that one will have an experience in the future to provide the same special boost of justification that actually having the experience provides. After all, according to Perceptual Partiality, knowing that someone else has the experience does not provide the same boost as actually having the experience oneself - and it seems that one's own future self should be no different from the Dogmatist point of view. For it is the actual experience itself, rather than any knowledge one has about the experience, which is supposed to be the distinctive source of justification.

But so then the problem for the Dogmatist is that increasing your confidence that the wall is red at the time you actually have the experience, when you knew already that you were going to have just that experience, seems to amount to a kind of 'diachronic' irrationality.

'For suppose that before noon you withhold belief that the wall is red, even though you know that at noon the wall will look red to you. It seems irrational for you suddenly to be convinced that the wall is red once your blindfold is removed and you seem to see a red wall. You knew that this would happen! More generally, it seems irrational for you to substantially increase your confidence at noon that the wall is red, merely because you are having the very experience that you knew in advance you would have.' (ibid., p22) 
The problem here is that the subject in ANTICIPATED EXPERIENCE will, if she increases her confidence as the Dogmatist suggests, violate what Van Fraassen $(1984,244)$ called 'Reflection':

\section{- REFLECTION: $\operatorname{Pr}_{\mathrm{t} 1}\left(\mathrm{~A} \mid \operatorname{Pr}_{\mathrm{t} 2}(\mathrm{~A})=\mathrm{n}\right)=\mathrm{n}$}

I.e. if at $\mathrm{t} 1$ you know that at $\mathrm{t} 2$ your confidence in $\mathrm{A}$ will $=\mathrm{n}$, then at $\mathrm{t} 1$ your confidence should already $=\mathrm{n}$. Van Fraassen showed that if you do not obey reflection then you are open to being diachronically Dutch-Booked - i.e. you will accept bets at different times that are guaranteed to lose money over that time-period ${ }^{3}$.

So in this 'Anticipated Experience' case: suppose you are a Dogmatist and at t1 you are suspending judgement whether there is a red wall before you. But you already know at t1 that: at $\mathrm{t} 2$ you will have an experience as of a red wall. So, by the Dogmatist's own lights, you can know at $\mathrm{t} 1$ that at $\mathrm{t} 2$ you will have some higher degree of confidence that there is a red wall before you (since you know at $\mathrm{t} 1$ that at $\mathrm{t} 2$ you will enjoy a confidence-boosting kind of experience). Which violates Reflection - as according to Reflection, you should already, at t1, adopt that higher degree of confidence.

\section{A response and an objection to it}

In what follows I want to defend the idea that the Dogmatist can 'bite the bullet' and simply accept that actually having an experience can rationally increase one's confidence, even if one knew beforehand that one would have that very experience.

For example: if someone whom you trust and take to be generally reliable tells you that you will have a red-wall-ish experience at noon, your confidence in the proposition: 'I'll have a red-wall-ish experience at noon' may be around 0.9 or 0.95 . Perhaps this relatively high level of credence counts as 'knowing' you will have such an experience at noon. But then when you actually have a red-wall-ish experience at noon (assuming you also know the time), your confidence in that proposition will become 1 or at least become extremely 'close" ${ }^{4}$ to 1 . And so, in turn, your new credence in the proposition that there is actually a red wall before you

\footnotetext{
${ }^{3}$ Notice: it is standardly allowed that such a principle is only plausible on the assumption that you do not lose evidence between $\mathrm{t} 1$ and $\mathrm{t} 2$ or suffer from memory loss etc.

${ }^{4}$ I include scare-quotes around the word 'close' here since the main point of this paper will be that the notion of 'closeness' to 1 is problematically measure-sensitive - see section 4 , below.
} 
could be higher when you actually have the red-wall-ish experience compared with merely learning beforehand that you are going to have this kind of experience.

This no longer seems to involve any kind of diachronic irrationality - for whilst $\mathrm{S}$ is pretty sure at $\mathrm{t} 1$ that she will have the experience at $\mathrm{t} 2$ (and thus that at $\mathrm{t} 2$ she will be confident that there is a red-wall before her), at $\mathrm{t} 1 \mathrm{~S}$ is still not as certain about the occurrence of the experience at $\mathrm{t} 2$ as she is at $\mathrm{t} 2$. So it could still be rational for $\mathrm{S}$ to become more confident that there is a red wall before her at $\mathrm{t} 2$, when she actually has the red-wall-ish experience, despite already being pretty confident at t 1 that this was going to happen.

Barnett rejects this response on the following grounds:

'I admit that this defense gives a plausible explanation of why your confidence might justifiably increase slightly at noon...

Even so, I think this defense cannot plausibly explain why one's degree of confidence for $\mathrm{p}$ could rationally increase more than slightly. If one knows that $\mathrm{e}$, then one has at most a little room for doubt about e. So there will be little room for one's degree of certainty in e to increase, and thus little room for one's confidence in $p$ to increase as a result of an increase in the certainty of e. This is important, because the anti-Cartesian proponent of PERCEPTUAL PARTIALITY needs to say that one's confidence that the wall is red can increase substantially at noon' (ibid., 25)

It matters for the Dogmatist that the extra 'proprietary justification' provided by actually having the experience is substantial, rather than just a slight increase, because one of the main motivations for Dogmatism (Anti-Cartesianism) is supposed to be its ability to help resist the Skeptic:

'...if having an experience offered only a slight increase in the strength of one's justification relative to what one would get from knowing about another person's experience, then the anti-Cartesian would have very limited anti-skeptical advantages over Cartesianism. For whatever the strength of our justification for perceptual beliefs might be under Cartesianism, the anti-Cartesian would be able to offer us only slightly more. That would be reassuring only if the skeptical worry was merely that we fall just slightly short of being justified in our perceptual beliefs! To have a noteworthy antiskeptical advantage, therefore, the anti Cartesian must claim that the proprietary justification conferred by one's experiences is substantial.' (ibid., 25-6) 
In a footnote (fn29) he adds:

'Although I take this point to be intuitively plausible, it can be reinforced by the familiar theorem of the probability calculus that $\operatorname{Pr}(\mathrm{p})=\operatorname{Pr}(\mathrm{p} \mid \mathrm{e}) \operatorname{Pr}(\mathrm{e})+\operatorname{Pr}(\mathrm{p} \mid \sim \mathrm{e}) \operatorname{Pr}(\sim \mathrm{e})$. Since $\operatorname{Pr}(\mathrm{p} \mid \sim \mathrm{e}) \operatorname{Pr}(\sim \mathrm{e}) \geq 0$, this theorem entails that $\operatorname{Pr}(\mathrm{p}) \geq \operatorname{Pr}(\mathrm{p} \mid \mathrm{e}) \operatorname{Pr}(\mathrm{e})$. So when for some $\delta$, $\operatorname{Pr}(\mathrm{e})=1-\delta$, it follows that $\operatorname{Pr}(\mathrm{p}) \geq \operatorname{Pr}(\mathrm{p} \mid \mathrm{e})(1-\delta)$, and thus that $\operatorname{Pr}(\mathrm{p}) \geq \operatorname{Pr}(\mathrm{p} \mid \mathrm{e})-\operatorname{Pr}(\mathrm{p} \mid \mathrm{e}) \delta$. And since $\delta \geq 0$ and $\operatorname{Pr}(\mathrm{p} \mid \mathrm{e}) \leq 1$, this means that $\operatorname{Pr}(\mathrm{p}) \geq \operatorname{Pr}(\mathrm{p} \mid \mathrm{e})-\delta$. Roughly put, the upshot is that $\operatorname{Pr}(\mathrm{p})$ can be less than $\operatorname{Pr}(\mathrm{p} \mid \mathrm{e})$ only to whatever extent $\operatorname{Pr}(\mathrm{e})$ is less than 1.' (ibid., 25)

\section{Log Odds and the 'Room for Doubt'}

The problem here is that this notion of there being only a 'little room for one's degree of certainty in e to increase' and so of having only 'little room for one's confidence in $p$ to increase' is an artefact of measuring/expressing subjective probabilities or degrees of confidence on the interval 0 to 1 . If we switch to expressing subjective probabilities in terms of Odds, or Log-Odds, the appearance of there being only 'a little room' left for confidence to increase vanishes. In other words, Barnett's claim is problematically measure-sensitive . $^{5}$ Moreover, there are some good (familiar) reasons to think that the Log-Odds scale provides a clearer picture of how new evidence can boost already high levels of confidence and so to treat the familiar 0-1 interval scale as apt to be misleading in this respect.

As well as expressing probabilities using numbers in the interval from 0 to 1 they can, of course, also be expressed as $O d d s$ - that is to say, as a ratio $\operatorname{Pr}(\mathrm{H}) / \operatorname{Pr}($ not-H). $\mathrm{I}$.e. $\operatorname{Pr}(\mathrm{H}) / \operatorname{Pr}(1-$ $\mathrm{H})$

One respect in which using Odds can be simpler or easier than using numbers in the 0-1 interval is that we can use the following simple formula:

- Posterior Odds $=$ Prior Odds $\mathrm{x}$ Likelihood ratio

Or in a more explicit formulation:

- $\quad \operatorname{Pr}_{\mathrm{NEW}}(\mathrm{H}) / \operatorname{Pr}_{\mathrm{NEW}}(\sim \mathrm{H})=\operatorname{Pr}_{\mathrm{OLD}}(\mathrm{H}) / \operatorname{Pr} r_{\mathrm{OLD}}(\sim \mathrm{H}) \times \operatorname{Pr}(\mathrm{e} \mid \mathrm{H}) / \operatorname{Pr}(\mathrm{e} \mid \sim \mathrm{H})$

\footnotetext{
${ }^{5}$ See Fitelson 1999 and Brössel 2013 for extended discussions of measure sensitivity.
} 
The likelihood ratio $-\operatorname{Pr}(\mathrm{e} \mid \mathrm{H}) / \operatorname{Pr}(\mathrm{e} \mid \sim \mathrm{H})$ - expresses how much more likely the occurrence of the evidence would be given that the hypothesis is true compared to how likely it would be if the hypothesis is false.

But notice: once we move to working with odds, probabilities are no longer expressed as numbers in the interval 0 to 1 , but rather from 0 to positive infinity. Already then, we have reason to be suspicious of the idea that when I am already very confident of a hypothesis e.g. the hypothesis that I will have a certain experience at noon - there is then only 'a little room' for my confidence to increase. When working with Odds there is always infinitely more 'room' for one's confidence to increase!

As well as working with odds, it can also sometimes be useful to work in 'Log-Odds'. If we take the logarithm of both sides of the equation above we get:

- $\log [$ Posterior Odds $]=\log [$ Prior Odds $]+\log [$ Likelihood ratio $]$

Or more explicitly:

- $\log \left[\operatorname{Pr}_{\mathrm{NEW}}(\mathrm{H}) / \operatorname{Pr}_{\mathrm{NEW}}(\sim \mathrm{H})\right]=\log \left[\operatorname{Pr}_{\mathrm{OLD}}(\mathrm{H}) / \operatorname{Pr}_{\mathrm{OLD}}(\sim \mathrm{H})\right]+\log [\operatorname{Pr}(\mathrm{e} \mid \mathrm{H}) / \operatorname{Pr}(\mathrm{e} \mid \sim \mathrm{H})]$

Notice: it doesn't matter what base we take for the logarithms. In the examples below we will use base 2, which allows us to talk of bits of evidence in line with the standard units of information theory. Shannon's notions of Entropy and Mutual Information are standardly measured in bits, which are computed with equations using logarithms of base 2 , though one could equally well use other bases. E.g. the natural logarithm is also often used, whilst Jaynes (2003) recommended using base 10 and so talking of decibels of evidence.

One respect in which the Log-Odds scale can be simpler or easier to use is that instead of multiplying the priors with the odds ratio, as in the Odds equation above, the Log-Odds equation requires only addition. The $\log$ of the likelihood ratio, $\log [\operatorname{Pr}(\mathrm{e} \mid \mathrm{H}) / \operatorname{Pr}(\mathrm{e} \mid \sim \mathrm{H})]$, thus provides a very natural way of expressing the boost in confidence that the evidence provides, so as to take you from your priors to your posteriors. I.e. it is a natural way of expressing the confirmatory strength of one's evidence. 
Using the Logarithm of the likelihood ratio as a measure of confirmation also has (at least) two other attractive features, which have been much-discussed in the literature on confirmation $^{6}$ :

(i) When we have lots of different independent pieces of evidence in favour of a hypothesis, using the log of the likelihood ratio makes the confirmation of each bit of evidence simply additive:

Confirmation of $\mathrm{H}$ by $\left(\mathrm{E}_{1} \& \mathrm{E}_{2} \& \mathrm{E}_{3} \& \ldots \mathrm{E}_{\mathrm{n}}\right)=\left(\right.$ Confirmation of $\mathrm{H}$ by $\left.\mathrm{E}_{1}\right)+($ Confirmation of $\mathrm{H}$ by $\left.\mathrm{E}_{2}\right)+\left(\right.$ Confirmation of $\mathrm{H}$ by $\left.\mathrm{E}_{3}\right)+\ldots \ldots\left(\right.$ Confirmation of $\mathrm{H}$ by $\left.\mathrm{E}_{\mathrm{n}}\right)$

(ii) Unlike nearly all other proposed measures of confirmation ${ }^{7}$, the log of the likelihood ratio satisfies the following two very highly plausible constraints on any theory of confirmation:

- SYMMETRY: Confirmation of $\mathrm{H}$ by $\mathrm{E}=$ Disconfirmation of $\sim \mathrm{H}$ by E. [i.e. the negative confirmation of $\sim \mathrm{H}$ by $\mathrm{E}]$

[And so: If [Confirmation of $\mathrm{H}$ by E1 > Confirmation of $\mathrm{H}$ by E2] Then [Confirmation of $\sim \mathrm{H}$ by E1 $<$ Confirmation of $\sim$ H by E2]

- LOGICALITY: All logical entailments of some $\mathrm{H}$ by some $\mathrm{E}$ have the same degree of confirmation, which is higher than any non-logically-entailing degree of confirmation.

[And so: all logical refutations are equally strong disconfirmation, which is stronger than any non-logical disconfirmation.]

And of course once we move to expressing probabilities using Log-Odds then they can vary from negative infinity to positive infinity. So there is always more 'room' for one's confidence to increase or to decrease. At this point, it is perhaps worthwhile to briefly give a graphic illustration of the difference between using the $0-1$ interval to express probabilities and using the Log-Odds Scale ${ }^{8}$.

\footnotetext{
${ }^{6}$ See Eells \& Fitelson 2000, 2002 for discussion and comparison of the main different candidate measures of confirmation that exist within a broadly Bayesian framework.

${ }^{7}$ See Crupi, Tentori, and Gonzalez 2007 for a different confirmation measure - the 'relative distance measure' - which also satisfies Symmetry and Logicality.

${ }^{8}$ The following diagrams are taken from the Mathematics website 'Arbital':

https://arbital.com/p/bayes_log_odds/
} 
Suppose that you initially think that some hypothesis, $\mathrm{H}$, is just as likely as its negation, $\sim \mathrm{H}$. So in the $0-1$ interval scale you have a credence in $\mathrm{H}$ of 0.5 ; or expressed as odds, a credence of 1:1; expressed in terms of Log-Odds, a credence of 0 bits. Now suppose that you get five separate independent, 2:1 updates in favour of H. I.e. 5 independent pieces of evidence for which $\operatorname{Pr}(E \mid H) / \operatorname{Pr}(E \mid \sim H)=2$. What is the effect of all these new pieces of evidence on your credences?

Your credences expressed in the $0-1$ interval go from: 0.5 to 0.67 to 0.8 to 0.89 to 0.94 to 0.97 (approx.)

Your odds for $\mathrm{H}$ go from 1:1 to $2: 1$ to $4: 1$ to $8: 1$ to $16: 1$ to $32: 1$

[[Recall: Posterior Odds $=$ Prior Odds $x$ Likelihood ratio $]]$

Graphically representing these changing probabilities on a line that goes from 0 to 1 :
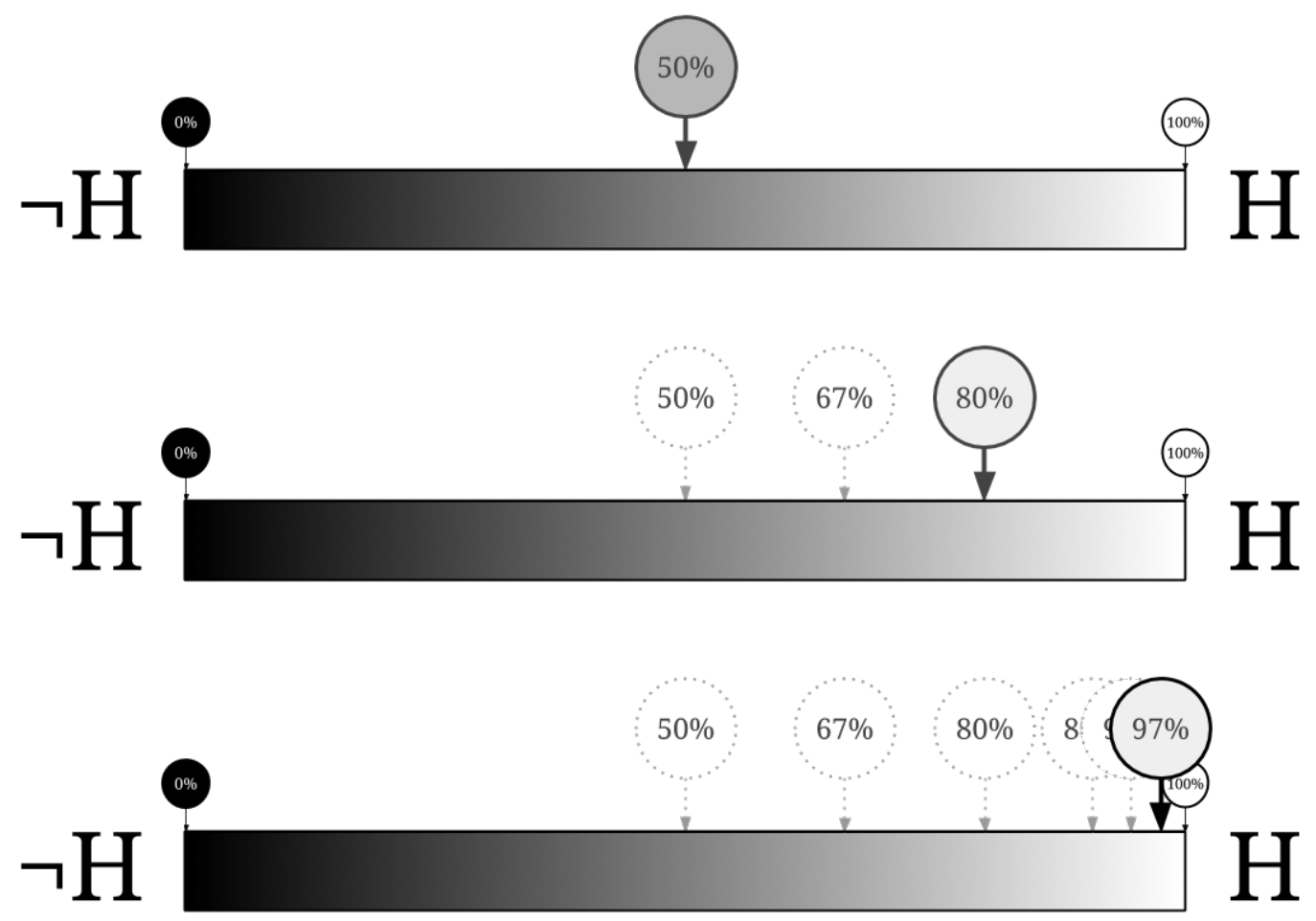

The probabilities approach 1 but never get there, they just keep stepping across a fraction of the remaining distance, eventually getting all 'scrunched up' near the right-hand end. If we instead convert the probabilities into log-odds, the picture is much clearer. 0.5 , or $50 \%$, 
probability becomes 0 bits of credence, and every independent 2:1 observation in favour of $\mathrm{H}$ shifts belief by one unit (bit) along the line.

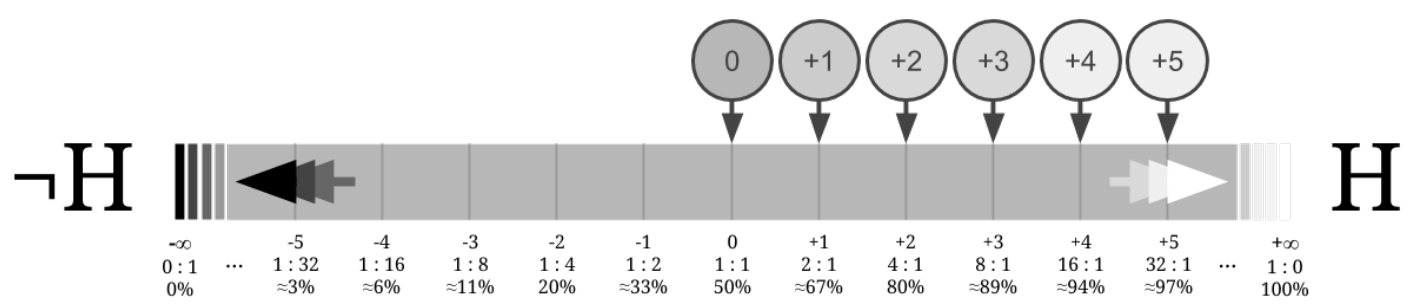

What is important for present purposes is that a change in confidence, when represented on the 0-1 interval, can appear to be only slight or insignificant if it occurs near to either extreme. But the very same change in confidence when represented on the log-odds scale can be seen to be significant. The increase in confidence from 0.94 to 0.97 , measured on the $0-1$ interval, is (roughly) equivalent to an increase from 4 bits to 5 bits of confidence measured in the Log-Odds scale - i.e. a confidence boost of 1 bit. Compare: An increase of confidence from 0.5 to 0.6666 is also equivalent to an increase of 1-bit. But here, in the middle of the $0-1$ interval, it is manifestly a significant increase in confidence.

Another way of making the same point: on the 0-1 scale, an increase from 0.5 and 0.50009 may appear to be of the same significance as an increase from 0.9999 and 0.99999. After all, it is an increase of 0.00009 in both cases, right? But if we think in terms of Odds, the former increase is equivalent to the change from 1:1 to $1.00036: 1$. Whereas the latter increase is equivalent to a change in Odds from 9999:1 to 99999:1. And in terms of Log-Odds, the increase from 0.5 to 0.50009 is a boost of only around 0.00052 Bits. Whereas, an increase from 0.9999 to 0.99999 is a boost of around 3.332 bits. Using the $0-1$ scale then can tend to compress and distort our intuitive sense of how much evidential strength is needed to move from one level of confidence to another; the strength of evidence needed to shift from 0.9999 to 0.99999 is massively more than that required to shift from 0.5 to 0.50009 .

Let's consider now how all this applies to the 'Anticipated Experience' case:

Suppose that merely learning beforehand, e.g. on the basis of reliable testimony, that you will have an experience as of a red-wall at noon - which proposition I will abbreviate to 'exp[red]' - gives you a $\operatorname{Pr}(\exp [\mathrm{red}])=0.95$. And suppose that actually having such an experience at noon increases this to $\operatorname{Pr}(\exp [\operatorname{Red}])=0.9999999$. Put in terms of $\log$ odds this would be an 
increase of 4 bits - it would be the same amount of evidential boost as going from 0.5 up to 0.95 .

I think this already shows that the first part of Barnett's objection - "If one knows that e, then one has at most a little room for doubt about e. So there will be little room for one's degree of certainty in e to increase" - can and should be resisted. When considered in terms of odds or $\log$ odds there is no lack of 'room'. There is ample 'space' for actually having the experience to make a very significant difference over merely learning that one will have the experience (e.g. from reliable testimony).

What about the second half of the objection Barnett makes: "and thus little room for one's confidence in $p$ to increase as a result of an increase in the certainty of e"?

Well, in order to deal with updating on evidence that is less than perfectly certain, we standardly use Jeffrey Conditionalising:

- $\quad \mathrm{P}_{\mathrm{NEW}}(\mathrm{H})=\left[\mathrm{P}_{\mathrm{OLD}}(\mathrm{H} \mid \mathrm{E}) \times \mathrm{P}_{\mathrm{NEW}}(\mathrm{E})\right]+\left[\mathrm{P}_{\mathrm{OLD}}(\mathrm{H} \mid \sim \mathrm{E}) \times \mathrm{P}_{\mathrm{NEW}}(\sim \mathrm{E})\right]$

In this case, the less-than certain evidence, $\mathrm{E}$, is the proposition that: I have an experience as of a red wall at noon, and the Hypothesis, $\mathrm{H}$, is that: There is a red wall before me. Lets now plug in some numbers to illustrate how an increase in confidence about $\mathrm{E}$ can plausibly result in a significant increase in confidence about $\mathrm{H}$, even if one already had a high confidence in E.

Suppose $\mathrm{P}_{\mathrm{OLD}}(\mathrm{H})=0.5$

Suppose $\mathrm{P}_{\mathrm{OLD}}(\mathrm{H} \mid \mathrm{E})=0.99$

Suppose $\mathrm{P}_{\mathrm{OLD}}(\mathrm{H} \mid \sim \mathrm{E})=0.5$

And now let's suppose that in the situation where I learn beforehand, via trusted testimony, that I will have an experience as of a red wall, my $\mathrm{P}_{\mathrm{NEW}}(\mathrm{E})=0.95$

So then, on the basis of this testimony, my $\mathrm{P}_{\mathrm{NEW}}(\mathrm{H})=(0.99 \times 0.95)+(0.5 \times 0.05)=0.9405+$ $0.025=0.9655$ 
But now suppose, by contrast, that actually having an experience as of a red wall makes my $\mathrm{P}_{\mathrm{NEW}}(\mathrm{E})$ extremely 'close' ${ }^{9}$ to 1 . I.e. $\mathrm{P}_{\mathrm{NEW}}(\mathrm{E}) \approx 1$

So then here my $\mathrm{P}_{\mathrm{NEW}}(\mathrm{H})$ is $\approx 0.99$

Given the above plausible-looking values, the difference between updating on mere foreknowledge via testimony of the experience vs. updating on the basis of actually having experiencing is (roughly) the difference between 0.9655 and 0.99 . Prima facie, and expressed thus as a value in the $0-1$ interval, this might seem only a 'slight' or 'insignificant' difference.

But, if we convert these two probabilities into Odds we get (roughly): 28:1 vs. 99:1.

Ask any gambler whether this is a 'significant' difference!

And if we convert these odds to log odds we get:

$\log _{2}(28) \approx 4.8 \quad \log _{2}(99) \approx 6.63$

So this is a difference of 1.83 bits, or, switching back to the $0-1$ interval, the same as the difference between 0.5 and 0.78 - i.e. the difference between even money and odds of nearly 4-to-1.

To repeat, the difference in confidence concerning $\mathrm{E}$ here results in a very significant difference in the confidence in $\mathrm{H}$. The evidential 'boost' that one receives from actually having the experience, compared with merely learning beforehand that one will have it, is nearly 2 whole bits of credence. The moral here: even if one is already very confident of $\mathrm{E}$, increasing one's confidence in E yet further can still result in a substantial, significant increase to one's confidence in $\mathrm{H}$.

\section{Summary \& Conclusion}

I have argued that the notion of having only 'little room left' for one's confidence to increase only seems plausible because we are expressing probabilities in the interval 0-1. If we switch to using Odds or Log-Odds, this appearance of there being only 'limited room' evaporates. Moreover, we have good independent reasons to think that the Log-Odds scale provides a better, clearer picture of the boost that a piece of evidence adds to one's prior probabilities so

\footnotetext{
${ }^{9}$ Again, the whole point of this example is that 'closeness' to 1 is a problematically measure-sensitive notion that arises when we use the $0-1$ interval to express probabilities.
} 
as to increase them to one's posterior probabilities. And when we use Log-Odds to express the increase in confidence that there is a red wall before one that results from actually having the red-wall-ish experience it becomes clear how this could indeed be a significant increase.

Thus, the Dogmatist's 'bullet-biting' response to the Anticipated Experience case remains a viable response - significantly increasing one's confidence that there is a red wall as a result of actually having the red-wall-ish experience need not involve any kind of diachronic irrationality, it can simply be the result of becoming more confident about one's evidence.

Of course, nothing I have said here is meant to provide a positive argument for endorsing either Dogmatism or Perceptual Partiality. I have only been arguing that Dogmatism and Perceptual Partiality can withstand the specific threat of diachronic irrationality that is posed by the ANTICIPATED EXPERIENCE case. For all that has been said here, there may well be other problems with Dogmatism and/or Perceptual Partiality - e.g. the much-discussed objection due to Roger White (2006), or see Hawthorne \& Lasonen-Aarnio (forthcoming) ${ }^{10}$.

\section{References}

- Barnett, D. (2019) 'Perceptual Justification and the Cartesian Theater', Oxford Studies in Epistemology 6: 1-34.

- Brössel, P. (2013) 'The Problem of Measure Sensitivity Redux', Philosophy of Science 80 (3): 378-397.

- Crupi, Tentori, and Gonzalez (2007) 'On Bayesian Measures of Evidential Support: Theoretical and Empirical Issues', Philosophy of Science 74 (2):229-252.

- Eells, E. \& Fitelson, B. (2000) 'Measuring Confirmation and Evidence', Journal of Philosophy 97 (12): 663-672.

- Eells, E. \& Fitelson, B. (2002) 'Symmetries and Asymmetries in Evidential Support', Philosophical Studies 107 (2): 129-142.

- Fitelson, B. (1999) 'The plurality of Bayesian measures of confirmation and the problem of measure sensitivity', Philosophy of Science 66 (3): 362-378.

- Hawthorne J. \& Lasonen-Aarnio, M. (forthcoming) 'Not so Phenomenal!'

- Jaynes, E. T. (2003) Probability Theory: The Logic of Science, Cambridge University Press.

- McDowell, J. (1994) Mind \& World, Oxford University Press

- Pritchard, D. (2012) Epistemological Disjunctivism, Oxford University Press

- Pryor, J. (2000) 'The Skeptic and the Dogmatist', Nous 34, 517-549.

- Van Fraassen (1984) 'Belief and the Will', Journal of Philosophy, 81: 235-256.

- White, R. (2006) 'Problems for Dogmatism', Philosophical Studies, 131: 525-557

\footnotetext{
${ }^{10}$ Earlier versions of this paper were presented at the conference 'Recent Debates in Formal Epistemology' at the University of Cologne and at the 2018 European Epistemology Network Meeting in Amsterdam. I am greatly indebted to discussions with the other members of the Emmy Noether Research Group ‘From Perception to Belief and Back Again': Peter Brössel, Insa Lawler, Jim Pryor and Filippo Vindrola. I am also very grateful to David Barnett for helpful correspondence - and for writing such an interesting paper in the first place. Finally, many thanks to two anonymous referees for this journal whose comments improved this paper.
} 